\title{
Research on Application of Cold Chain Logistics Management Based on Big Data Technology
}

\author{
Na Li, Wei Yao \\ School of Intelligent Manufacturing And Service \\ Shandong Institute Of Commerce And Technology \\ Jinan 250103, China
}

\begin{abstract}
Compared with developed countries, the cold chain logistics of agricultural products in china is wasteful, which not only consumes a lot of labor and natural resources, but also reduces the domestic and international competitiveness of agricultural products. The paper analyzes outstanding issues such as cold chain "broken chain", "information islands", and cold chain "food safety". Through the integration of advanced information technologies such as big data and mobile internet, a cold chain logistics engineering management technology platform is established to establish a national The data analysis center and the national cold chain logistics big data real-time monitoring and early warning platform, open up the logistics information chain, realize the full traceability of logistics information, promote the effective docking of logistics information and public service information, and encourage the sharing of information on logistics platforms between regions and industries. interconnection.
\end{abstract}

\section{INTRODUCTION}

In the past few decades, china's economic growth patterns mainly include resource-consuming, laborintensive, environmental pollution, large-scale investment, and large-scale export-oriented low-end products [1]. As a part of modern logistics, cold chain logistics of agricultural products has long been lacking in cold storage at the origin and professional cold chain warehousing, distribution centers (DC) and third-party logistics (TPL), severe chain disconnection, and lack of new technology and new model support. The huge waste, coupled with the $80 \%$ of china's primary agricultural products exports, not only consumes a lot of labor, but also consumes natural resources such as land and water conservancy, and reduces the domestic and international competitiveness of the products. On January 20, 2017, the General Office of the State Council issued the "Opinions on Innovative Management, Optimizing Services, Cultivating and Growing New Drivers of Economic Development and Accelerating the Conversion of New and Old Drivers", which clearly stated that accelerating the cultivation and growth of new drivers of economic development, and accelerating the conversion of new and old drivers is to promote the economy. An important approach to structural transformation and upgrading of the real economy is an important focus of advancing supply-side structural reforms. Therefore, clarifying the influencing factors of agricultural cold chain logistics loss can theoretically provide a reference for cold chain logistics operation practice, which has important practical significance for reducing agricultural product loss and waste and realizing the conversion of new and old kinetic energy of agricultural cold chain logistics. In order to solve the problems in the above methods, a method for real-time monitoring and optimization of big data in cold chain logistics distribution is proposed.

\section{ANALYSIS OF THE STATUS QUO OF COLD CHAIN LOGISTICS}

\subsection{The rapid development of cold chain logistics}

china is a big country in agricultural production and agricultural products consumption. At present, the output of vegetables accounts for about $60 \%$ of the total global output, the output of fruits and meat accounts for $30 \%$, and the output of poultry, eggs and aquatic products accounts for $40 \%$. In recent years, China's refrigerated and frozen food production has increased by about $10 \%$ each year, and about 400 million tons of fresh agricultural products enter the circulation field each year. The proportion of cold chain logistics has gradually increased. At present, the cold chain circulation rate of fruits, vegetables, meat, and aquatic products in China has reached $5 \%, 15 \%$ and $23 \%$, the refrigerated transportation rate reached $15 \%, 30 \%$, and $40 \%$ respectively, and the scale of cold chain logistics increased rapidly [2]. The low-temperature treatment of 
processing and cooling mature links started, and gradually extended to storage, transportation, wholesale and retail links, and developed rapidly in the direction of full-process low-temperature control.

\subsection{Large gap compared with developed countries}

At present, the cold chain circulation ratio of agricultural products in china is far lower than that of developed countries in Europe and America. Most of china's fresh agricultural products are still in circulation at room temperature, as shown in Table 1.

TABLE I. COMPARISON OF COLD CHAIN LOGISTICS BETWEEN CHINA AND FOREIGN COUNTRIES (TAKE FRUITS AND VEGETABLES AS AN

\begin{tabular}{|c|c|c|c|c|c|}
\hline \multicolumn{6}{|c|}{ EXAMPLE) } \\
\hline Country & $\begin{array}{c}\text { The proportion of } \\
\text { refrigerated and insulated } \\
\text { vehicles in the vehicle } \\
\text { ownership of freight } \\
\text { enterprises }\end{array}$ & $\begin{array}{l}\text { Fruit and vegetable } \\
\text { circulation rate }\end{array}$ & $\begin{array}{c}\text { Refrigerated } \\
\text { transportation } \\
\text { rate }\end{array}$ & $\begin{array}{l}\text { Fruit } \\
\text { loss } \\
\text { rate }\end{array}$ & $\begin{array}{l}\text { Vegetable } \\
\text { loss rate }\end{array}$ \\
\hline China & $0.30 \%$ & $5 \%$ & $15 \%$ & $20 \%$ & $30 \%$ \\
\hline United States & $1 \%$ & $95 \%-100 \%$ & $100 \%$ & $1.70 \%$ & $5 \%$ \\
\hline Developed country average & $1 \%-3 \%$ & $90 \%-100 \% 80 \%-90 \%$ & $80 \%-90 \%$ & $5 \%$ & \\
\hline
\end{tabular}

\section{PRINCIPLES OF REAL-TIME MONITORING OF BIG DATA IN COLD CHAIN LOGISTICS DISTRIBUTION}

The current big data real-time monitoring method of cold chain logistics distribution takes the CV model as the target motion model of cold chain logistics distribution big data. The particle filter algorithm is used to collect the weighted particle set through the posterior probability, and the posterior distribution is expressed, and the summation form is used to replace the integral to complete the real-time monitoring of big data of cold chain logistics and distribution. It is assumed that the movement rate of the target data in the cold chain logistics distribution process is fixed. The expression of motion equation of cold chain logistics distribution big data target tracking formed by $\mathrm{CV}$ model is

$$
X_{k}=\Phi_{k} X_{k-1}+G_{k} w_{k}
$$

In the formula, $X_{k}$ represents the state vector of the target data, in which there are speed and position; $w_{k}$ represents the process noise in the cold chain logistics distribution big data; $\Phi_{k}$ and $G_{k}$ represent the state vector and process noise, respectively The gain matrix. Assuming that the signal energy of cold chain logistics target data is collected by the sensor node, the signal energy received by the $\mathrm{i}$-th sensor node at time $\mathrm{t}$ is $z_{k}^{i}$, and the calculation formula of $z_{k}^{i}$ is

$$
z_{k}^{i}=\gamma_{i} S_{k} /\left\|L_{K}^{T}-L^{i}\right\|^{\alpha}+n_{k}^{i}
$$

In the formula, $L_{K}^{T}$ represents the location of the target data, $L^{i}$ represents the location of the node; $S_{k}$ represents the signal energy generated by the target data; $n_{k}^{i}$ represents the measurement noise; $\gamma_{i}$ represents the gain factor of the $\mathrm{i}$-th sensor node ; $\alpha$ represents the attenuation parameter of signal energy. Assuming that the dynamic clustering structure has been constructed at the initial moment, $\mathrm{M}$ represents the total number of $\mathrm{CN}$ sub nodes in the current cluster; $n_{j}$ represents the total number of particles allocated in the jth $\mathrm{CN}$ node, and $p\left(x_{0} \mid z_{0}\right)$ represents the prior probability. The cold chain logistics distribution big data is collected $p\left(x_{0} \mid z_{0}\right)$, and the initial particle set is uniformly distributed, so that the weights of the distributed particles are the same. Let $x_{k-1}^{i, j}$ represent the particle set at a moment before time $\mathrm{k}$, and use the state equation $\mathrm{K}$ to predict the state of the target data and collect new particles

$$
x_{k-1}^{i, j} \sim q\left(x_{k} \mid x_{k-1}^{i, j}, z_{k}^{i}\right)=p\left(x_{k} \mid x_{k-1}^{i, j}\right)
$$

In the formula, $q\left(x_{k} \mid x_{k-1}^{i, j}, z_{k}^{i}\right)$ represents the posterior probability of the target data. Let $w_{i}, j_{k}$ represent the weight of the particle. When node $\mathrm{CN}$ collects the observations of the current cold chain logistics distribution data, the weight of the particle is calculated

$$
w_{k}^{i, j}=w_{k-1}^{i, j} p\left(z_{k}^{i} \mid x_{k}^{i, j}\right)
$$

In the formula, $p\left(z_{k}^{i} \mid x_{k}^{i, j}\right)$ is the state equation of signal energy. Calculate the aggregated data of the jth $\mathrm{CN}$ :

\section{SPARSE SAMPLING MODEL OF COLD CHAIN LOGISTICS PERCEPTION DATA BASED ON BIG DATA}

The wireless sensor node in cold chain logistics exchanges information with the sink node through the wireless communication network. Sensor nodes are densely distributed in the monitored area. The floatingpoint temperature and humidity signals collected by the same temperature and humidity sensors at different nodes meet the characteristics of continuous and segmented smoothness in the time domain, and they are spatially similar. According to the temporal and spatial characteristics of temperature and humidity signals, wavelet transform can well realize the sparse representation of sensor data.

In order to achieve compressed sampling of monitored sensor data, a sparse sampling model needs to 
be constructed according to the characteristics of the sensor data. The specific steps of the model construction are shown in the dashed box in Figure 1.

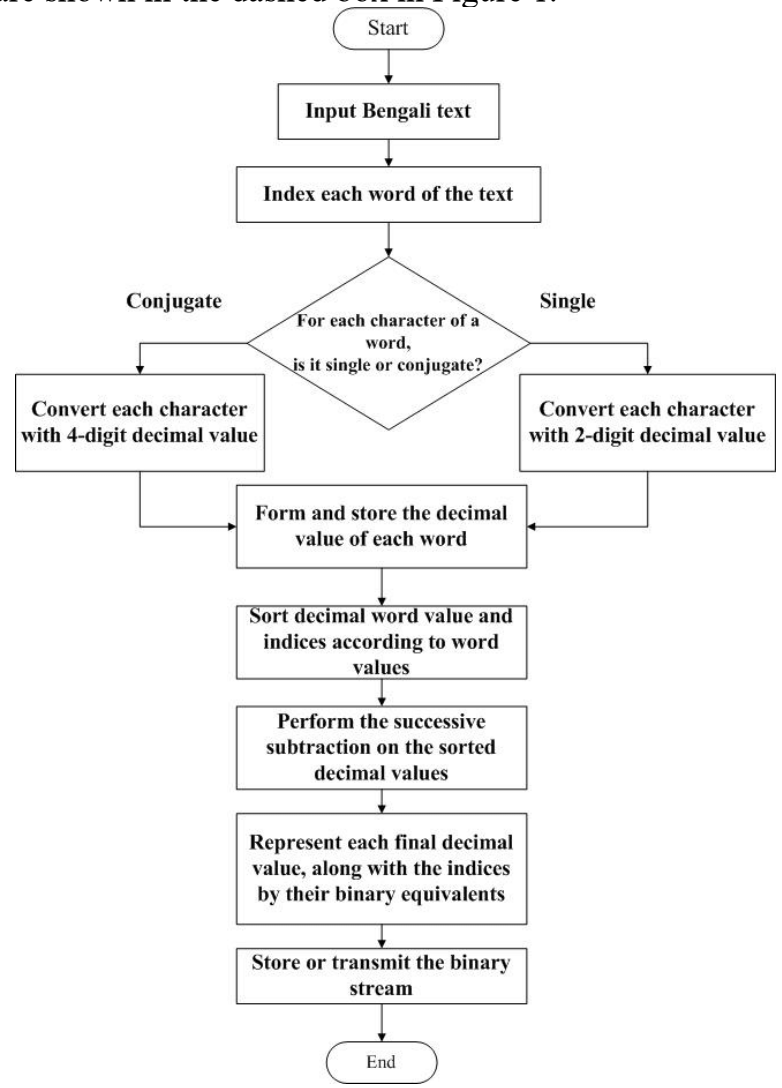

Figure.1. Data compression transmission flow chart

\subsection{Transmission model in cold chain logistics}

Assuming that $\mathrm{D}$ is a collection of all sensor nodes, the specific steps of data transmission model construction in cold chain logistics are shown in Figure 1, and the transmission process is shown in Figure 2. The sensor node in the refrigerated truck collects and uploads the data while receiving the control instructions from the sink node. The data is compressed and observed by the sink node and then transmitted to the remote receiving terminal via GPRS. The receiving terminal completes the high-precision data through the reconstruction algorithm Refactoring [3].

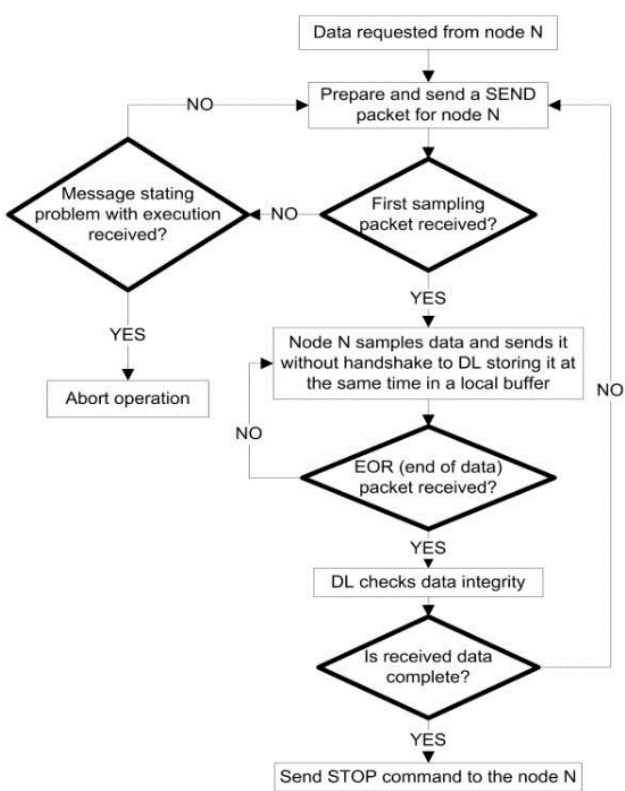

Figure.2. Data transmission process diagram

\subsection{Cold chain logistics perception data reconstruction model}

After the sensor data is transmitted to the receiving terminal after observation and compression, the compressed data needs to be reconstructed. The data reconstruction adopts the orthogonal matching pursuit (OMP) algorithm, which is a typical method to solve the reconstruction problem of compressed sensing. The basic idea is as follows shown in Figure 3.

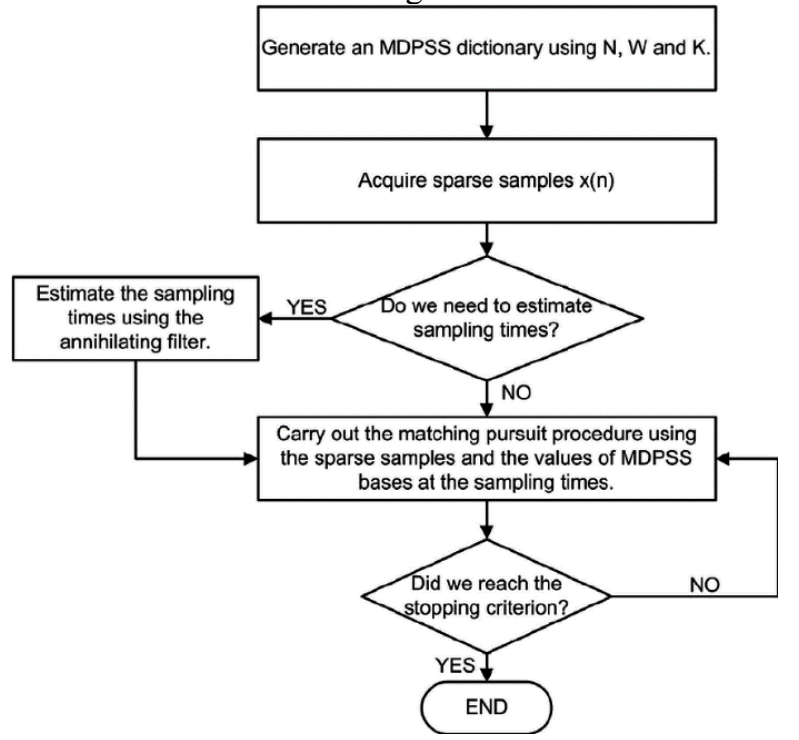

Figure.3. Flow chart of matching pursuit algorithm

The OMP algorithm knows the observation matrix $\Phi$, the sparse transformation matrix $\Psi$, and the observation value $y$, and solves the sparse representation coefficient Fs of the signal $\mathrm{x}$ in $\Psi$.

\section{SYSTEM DESIGN AND IMPLEMENTATION}

According to the above model, the software and hardware of the cold chain logistics wireless sensor network system for table grapes are developed, and 
integrated testing is performed to make the system run stably and the comprehensive performance indicators meet the design requirements. The hardware structure of the system is shown in Figure 4. The system uses the sink node to act as a time reference point and sends synchronization information containing the current clock reading [4]. After each node receives the synchronization information, it estimates its own time delay and corrects the clock value once. When receiving the control command sent by the sink node, the node in the dormant state is immediately awakened and the clock synchronization is completed, and then the data collection and transmission are completed. Because the timers of sensor nodes inevitably have timing differences, to ensure timely activation, each node is set to wake up $2 \mathrm{~s}$ earlier. When the node receives the confirmation signal ACK sent by the sink node, it goes to sleep again and waits for the next wake-up.

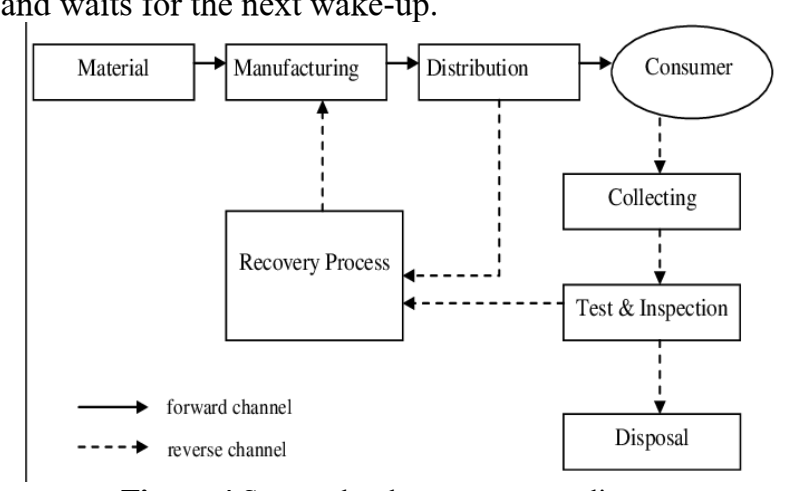

Figure.4.System hardware structure diagram

The node that has not received the confirmation signal continues to collect and send until it is received. When all nodes receive the confirmation signal, the sink node performs observation compression processing of the data. The temperature and humidity measurement adopts the digital temperature and humidity sensor SHT11 from Sensation, Switzerland. The temperature and humidity measurement ranges are $-40 \sim 123.8^{\circ} \mathrm{C}$ and $0 \sim 100 \%$ respectively, and the measurement accuracy is $\pm 0.4^{\circ} \mathrm{C}$ and $\pm 3.0 \%$ respectively.

The design of the sink node is compared with the sensor node. In addition to the management of the network and the observation and compression of the data, the sink node must also realize the remote transmission of data. Therefore, the CC2530 of TI is used as a network coordinator to communicate with each node on the one hand, and it also communicates with the ZWG-28DP embedded industrial-grade GPRS wireless module with small size and flexible application through the serial bus. CC2530 supports multiple protocol standards such as IEEE802.15.4 and ZigBee. The chip integrates a $2.4 \mathrm{GHz}$ standard radio frequency transceiver, an enhanced 8051 single-chip microcomputer, and a $256 \mathrm{kB}$ system programmable flash memory, which fully meets the realtime monitoring of sensor nodes and the compressed observation of aggregation nodes in the cold chain logistics process of table grapes. At the same time, it also has 8 channels of 12-bit ADC, 2 UART ports and 21 general-purpose $\mathrm{I} / \mathrm{O}$ ports. The product size is $6 \mathrm{~mm} \times 6 \mathrm{~mm}$, and the volume is small, which is conducive to the design integration and optimization of the system circuit. It also has lower power consumption. The receiving current in active mode is $24 \mathrm{~mA}$, and the $1 \mathrm{~dB}$ sending current is $29 \mathrm{~mA}$, which can adapt to a wide DC voltage of $2.0-3.6 \mathrm{~V}$, which is conducive to the long-term operation of the system [5].

\section{EXPERIMENTAL RESULTS AND ANALYSIS}

In order to verify the overall effectiveness of the cold chain logistics distribution big data real-time monitoring optimization method, it is necessary to test the cold chain logistics distribution big data real-time monitoring optimization method. The operating system memory in this experiment is $16 \mathrm{~GB}$, and the hard disk capacity is 500GB. The test results are shown in Table 2.

TABLE II. THE CREDIBILITY OF THE DYNAMIC CHARACTERISTICS OF THE THREE DIFFERENT METHODS

\begin{tabular}{|c|c|c|c|}
\hline \multirow{2}{*}{ CS } & \multicolumn{3}{|c|}{ QZ } \\
\cline { 2 - 4 } & LL & RF & DW \\
\hline 1 & 8 & 7 & 4 \\
\hline 2 & 9 & 7 & 4 \\
\hline 3 & 8 & 6 & 5 \\
\hline 4 & 8 & 5 & 6 \\
\hline 5 & 9 & 5 & 4 \\
\hline 6 & 9 & 6 & 4 \\
\hline PJ & 8.5 & 6 & 4.5 \\
\hline
\end{tabular}

In Table 2, QZ represents the dynamic feature weights of cold chain logistics and distribution big data; LL represents the real-time monitoring and optimization method of cold chain logistics and distribution big data; RF represents the cold chain logistics and distribution big data monitoring based on RFID technology Method; DW represents the cold chain logistics distribution monitoring method based on large-dimensional data; CS represents the number of experiments in three different methods; PJ represents the average dynamic characteristics of cold chain logistics distribution big data obtained by three different methods Weight. Analyzing the data in Table 1, we can see that the dynamic feature weights obtained by the cold chain logistics distribution big data real-time monitoring optimization method in the 6 iterations are 8 , $9,8,8,9$, and 9, respectively, and the average dynamic feature weights are 8.5; The dynamic feature weights obtained by the large data monitoring method of cold chain logistics distribution based on RFID technology are $7,7,6,5,5,6$, respectively, and the average dynamic feature weight is 6 ; using large-dimensional data The dynamic feature weights obtained by the cold chain logistics distribution monitoring method are 4, 4, 5, 6, 4, 4 , and the average dynamic feature weight is 4.5 . Comparing the average dynamic feature weights of three different methods, it can be seen that the dynamic feature weights obtained by the real-time monitoring and optimization method of cold chain logistics distribution big data are higher than those based on RFID technology and the cold chain logistics distribution big data monitoring method based on large-dimensional data. The dynamic feature weights of the cold chain logistics distribution monitoring method verify that the dynamic features obtained by the cold chain logistics distribution big data real-time monitoring optimization method have high credibility [6]. The comparison results are shown in Figure 5. 

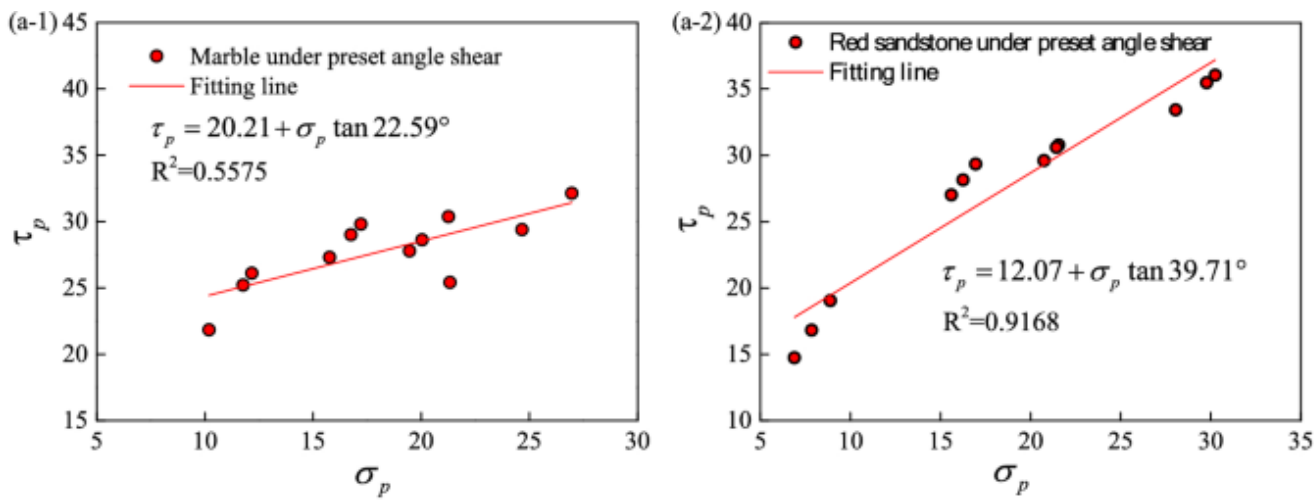

(a) Fitting lines for the preset angle shear test results
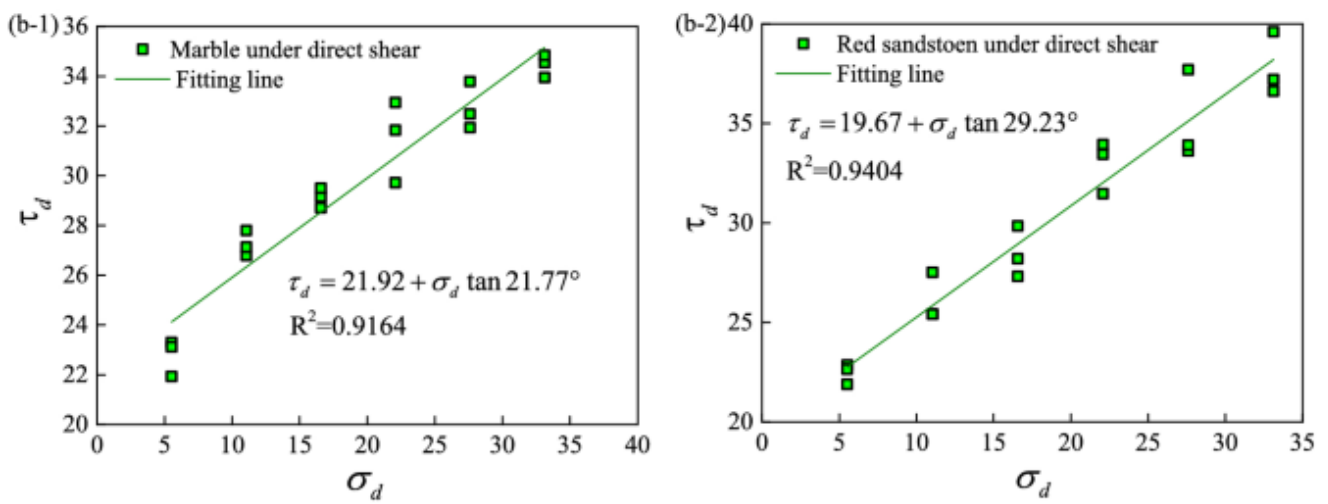

(b) Fitting lines for the direct shear test results
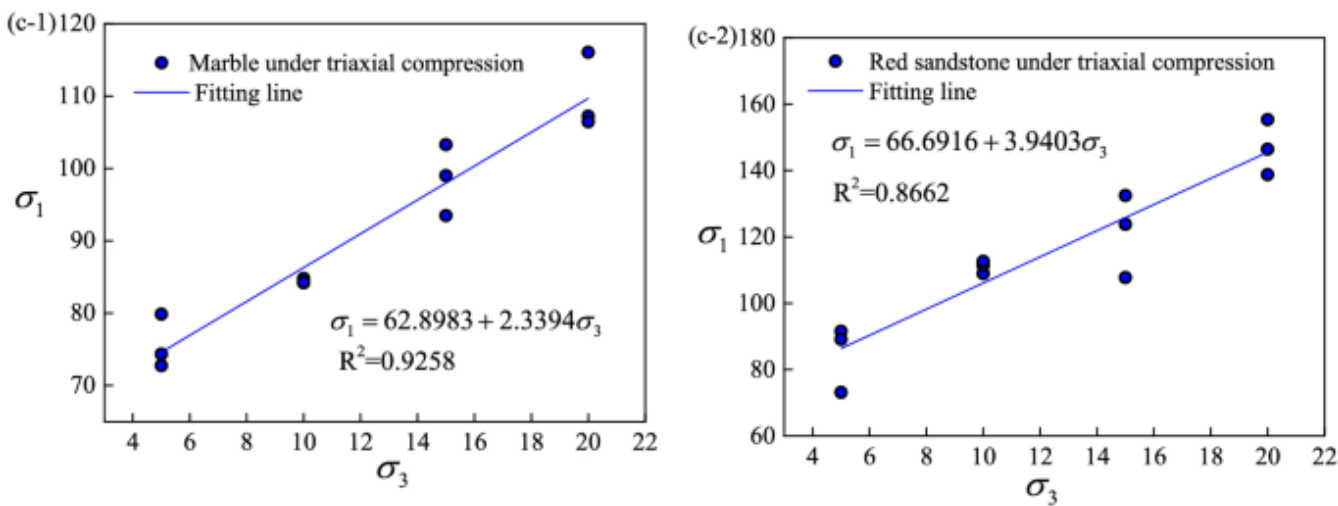

(c) Fitting lines for the triaxial compression test results

Figure.5.Test results of three different methods

Figure 5(a) is a comparison diagram of the measured location obtained by using the cold chain logistics distribution big data real-time monitoring optimization method and the actual location of the cold chain logistics distribution big data. Analysis of Figure 5(a) shows that the cold chain logistics distribution big data real-time the measurement position obtained by the monitoring optimization method almost coincides with the actual position. It is verified that the real-time monitoring and optimization method of cold chain logistics distribution big data can accurately locate the data and complete the real-time monitoring of the cold chain logistics distribution big data. Figure 5(b) and Figure 5(c) are the comparison diagrams of the measured position and the actual position obtained by the cold chain logistics distribution monitoring method based on RFID technology and the cold chain logistics distribution monitoring method based on large-dimensional data, respectively. Figures 5(b) and 5(c) show that the measured position obtained by the above two methods has a large deviation from the actual position, which verifies that the accuracy of the target positioning result of the cold chain logistics distribution big data real-time monitoring optimization method is high.

\section{Conclusion}

In order to reduce the large amount of inventory and waste caused by excessive blind production, china urgently needs to use big data technology and statistical forecasting technology to guide macro production. As a micro enterprise, it is necessary to actively use operations 
research technology to make optimal decisions on cold chain investment, cold chain warehousing, inventory, distribution routes, and time. In optimizing decisions, pay particular attention to the relationship between cold chain investment, temperature control, and carbon emissions. Relationship, not only strengthens investment and temperature control, but also avoids carbon emissions caused by excessive cooling. Furthermore, to give full play to the professional functions of DC/TPL, cold chainrelated companies must actively seek to achieve win-win and common prosperity in cooperative alliances, and strengthen communication and connection with various advanced information technologies and information sharing, which will reduce the entire cold chain link. In addition, the rapid response of the entire cold chain and intelligent high-end services have been realized in order to improve the quality of fresh products and promote consumption upgrades in the process of reducing the loss and waste of fresh products and their carbon emissions.

\section{REFERENCES}

1. Clarke, D., \& Branscomb, J. Development of a novel cold chain tubing, fp-flex, and freezing bag for cell therapy closed-system processing, storage and transport to temperatures as low as $196^{\circ} \mathrm{c}$. Cytotherapy, vol. 17, pp. S78-S78, June 2015.
2. Verma, S., Bhattacharyya, S. S., \& Kumar, S. An extension of the technology acceptance model in the big data analytics system implementation environment. Information Processing \& Management, vol. 54, pp. 791-806, May 2018.

3. Brunke, S., Quintin, J., Kasper, L., Jacobsen, D., \& Richter, E. Of mice, flies - and men? comparing fungal infection models for large-scale screening efforts. Disease Models and Mechanisms, vol. 8, pp.473-486, May 2015.

4. Dabrowski, S., Staat, C., Zwanziger, D., Sauer, R. S., Bellmann, C., \& Günther, Ramona, et al. Redoxsensitive structure and function of the first extracellular loop of the cell-cell contact protein claudin-1: lessons from molecular structure to animals. Antioxidants \& Redox Signaling, vol. 22, pp.1, January 2015.

5. Nativi, S., Mazzetti, P., Santoro, M., Papeschi, F., Craglia, M., \& Ochiai, O.Big data challenges and solutions in building the global earth observation system of systems (geoss). Environmental Modelling \& Software, vol. 68, pp.1-26, June 2015.

6. Chang, V. Towards a big data system disaster recovery in a private cloud. Ad Hoc Networks, vol. 35, pp. 65-82, December 2015. 